\title{
Studies on Effects of Nutrient Supplements Fortified with Phagostimulants Formulation H1 on Growth and Development of Indoor Reared Antheraea assamensis Helfer (Lepidoptera: Saturniidae)
}

\author{
Himangshu Barman (Corresponding author) \\ Central Muga Eri Research \& Training Institute \\ Central Silk Board, M/O Textiles, Govt. of India \\ Lahdoigarh, Jorhat, Assam, India
}

Tel: 91-98-6402-3840_E-mail: himangshu_barman1@rediffmail.com

Rama Krishna Rajan

Central Muga Eri Research \& Training Institute

Central Silk Board, M/O Textiles, Govt. of India

Lahdoigarh, Jorhat, Assam, India

Tel: 91-9435-052-535

The paper is the outcome of indoor rearing of Muga silkworm project AIP 5844 sponsored by Central Silk Board, Ministry of Textiles, Government of India.

\begin{abstract}
A phagostimulant formulation $\mathrm{H} 1$ was fortified with different combinations of ascorbic acid, proline and Sodium Cyclamate to study their effect on growth and development of Muga silkworm under indoor rearing. All the chemicals fortified with formulation $\mathrm{H} 1$ had positive effect on body tissue growth of Muga silkworm, the best fortified combination being ascorbic acid-proline that gave highest average tissue growth of $2.8861 \mathrm{~g}$ against the average tissue growth of $2.55934 \mathrm{~g}$ in control. In larval survivability, the fortified nutrient combination ascorbic acid - proline and ascorbic acid - Na cyclamate had profound effect in all the instars. In respect of cocoon qualities, measured as cocoon weight, shell weight and silk ratio, all the nutrient combinations with phagostimulant formulation H1 were high in contrast to control. Leaf extract of Som plant has positive effect if used in the spray solution as substitute of blank water.
\end{abstract}

Keywords: Phagostimulant, Formulation H1, Ascorbic acid, Proline, Sodium cyclamate, Leaf extract, Spray solution

\section{Introduction}

Being heterotrophy, insects must consume other organisms either plant or animal in order to acquire energy-rich molecules needed. Findings of a good number of workers depicted insect's dietary requirements as carbohydrates, proteins, lipids, nucleotides, vitamins, minerals besides water as essential component. Carbohydrate requirements include polysaccharides such as starch, glycogen, chitin, celluloses; oligosaccharides including sucrose, trehalose and, simple sugar like glucose, galactose, and fructose. Complex carbohydrates like as chitin, celluloses are digested by enzymes secreted by symbiotic bacteria and protozoa living inside their digestive tract. Motoyuki Sumida et al. (2007) found that dietary sucrose functions as an effecter molecule to midgut cells in the 5th instars $B$. mori larvae and as an output response, produces suppressed surcease protein. The highest activity was observed with $3 \%$ sucrose diet and it was higher than the control, indicating apparent activation. Phytophagous insect must process large volumes of plant sap in order to extract enough proteins to meet their metabolic needs. Protease enzymes in insects digestive system break down proteins into constituent amino acids which are in turn used by cells to build enzymes and hormones as well as proteins needed for muscle, egg yolk, ribosome, cuticle and many other purposes. As ten essential amino acids like lysine, tryptophan, histidine, phenylalanine, leucine, isoleucine, threonine, methionine, valine, and arginine that cannot 
be synthesised from other amino acids or similar chemical building blocks, must be supplemented in insect feed. Proteins required by insects are actins, myosin, resilin, arthropodin enzymes, hormones, ribosome and peptides like brain hormone, bursicon. It is usually true with the insect larvae that the nitrogen content of the early stages is greater than later stages. Lipids are important in the later larval stages for survival, reproduction, and development (Nation, 2001; Chapman, 1998). Lipid compounds for insect growth and development are fats, fatty acids and steroids. The fats molecule through enzymatic breakdown by lipase in the mid gut releases energy required by insect body for various life processes. Fatty acids also serve as building blocks for cuticle's waxes and the glandular synthesis of certain pheromones and defensive compounds. Insects appear to lack enzymes for metabolic pathway of steroid synthesis and they must obtain steroid compounds especially cholesterol, directly from their diet. Steroid building blocks are used to make hormones like ecdysteroids and growth factors. Insects feeding on steroid-deficient diets generally survive as immature but fail to moult properly into the adult stage. Lipids, phospholipids, triglycerides, sterols, sterol esters and fatty acids are usually important phagostimulants for many different insects (Nation, 2001). For nutrition, insect body also have the requirement of nucleic acids, purines, pyrimidines, mono-nucleotides and di-nucleotides.

In addition insects also acquire water, vitamins, and minerals from their food. Most insects are highly-adapted for water conservation and get most of the water they need directly from their food. Insects usually require a good source of seven vitamins: thiamine, riboflavin, nicotinic acid, pyridoxine, pantathenic acid, folic acid, and biotin, in small amounts, because they can't synthesize the vitamins. The deficiency of carnitine cause molting difficulties and fatty acids degradation of midgut and (House, 1965). Insects have the dietary requirements of minerals in very small amount such as iron, copper, calcium, sodium, potassium ions, phosphorus, and sulphur. Given the known composition of insects, it is reasonable to assume that sodium, potassium, calcium, magnesium; chloride and phosphate are essential minerals for the function of insects (Nation, 2001). Many phytophagous insects need quite large amount of potassium and only trace amounts of sodium (Nation, 2001).

The balance of nutrients is very important to most studied insects (House, 1965; Dadd, 1985). Balance may be important due to small body size and the stress placed on several physiological systems by having to deal with excesses while attempting to accumulate suboptimal levels of the major nutrients (Genc, 2006). According to Spencer T. Behmer (2009) most phytophagous insects strongly regulate their nutrient uptake and in case of imbalanced diets, they employ regulatory rules that govern the extent to which nutrients occurring in excess or deficit are eaten.

It has been found by several researchers that if these nutrient chemicals are synergised by other constituents that enhance their phagostimulatory effect well above that of nutrient phagostimulants. Perhaps the combined phagostimulatory effect is greater than that of nutrients in the plant. This effect could arise through the interaction of chemicals at the insects sensory receptors so that the sign stimulus dominates the information that the insect receives. So in the present context of studies, certain nutrient supplements fortified with insect phagostimulants (phagostimulant formulation H1) were attempted in growth and development of Muga Silkworm (Antheraea assamensis Helfer).

\section{Materials and method}

Some chemicals with Phagostimulatory effects, already found positive on growth and development of Muga Silkworm in a formulation termed as H1, were fortified with different combinations with ascorbic acid, proline, sodium cyclamate and Som (Persea bombycina) leaf extract and, prepared stock solutions in sterilized distilled water designated as solution-1, solution-2, solution-3, solution-4 and solution-5. The concentration of all chemicals including formulation H1 remained same in these solutions. Solution-1 contained phagostimulant formulation H1, ascorbic acid, proline and sodium cyclamate. Solution-2 had the same constituents except Som leaf extract in place of distilled water. Other solutions were also same with solution-1 except each one missing one chemical constituent i. e. solution -3 and solution-4 missed ascorbic acid and proline respectively, while solution-5 did not included sodium cyclamate. These stock solutions were kept in refrigerator for 48 hours after preparation.

Three years old healthy potted Som (Persea bombycina) plants, grown separately in 6 nos. cemented pot, were selected and brought to indoor veranda of the laboratory. These were labelled as T1, T2, T3, T4, T5 and T6 corresponding respective spray solutions. The potted plant labelled as T6 was treated as control. Prior to brushing, spray solutions were prepared by diluting 10 times of each stock solution separately in hand poly sprayers, so as the concentration of ascorbic acid, proline and sodium cyclamate became $0.5 \%, 0.2 \%$ and $1.0 \%$ respectively. All the plants except T6 were sprayed with respective spray solutions 24 hours before brushing newly hatched out Muga Silkworm (Antheraea assamensis Helfer) larvae. Muga Silkworm disease free layings 
(dfls) were hatched by 'Black Boxing' method. Newly hatched out larvae were brushed on each potted plants @ 125 nos. per treatment. Every day from the date of brushing onwards plants were prayed two times in a day with respective spray solutions. Plant considered as control was not sprayed with any solution. During moulting times sprayings were avoided. Continuous feeding by larvae was maintained by replacing with new suitable potted Som plants. The average larval weight of just moulted out larvae were taken at each instars. Similarly, larval survivability in all the treatments was recorded separately at the end of each instar. The cultures were maintained as such up to cocooning.

\section{Results and discussion}

Results of different treatments with fortified solutions on larval weight, larval survivability, effective rate of rearing, cocoon weight, shell weight and silk ratio are tabulated in table -1. From the tabulated results it has been observed that $1^{\text {st }}$ instar larval weight increased significantly over T6 in all spray treatment except T5. In $4^{\text {th }}$ and $5^{\text {th }}$ instars larval weight in contrast to control (T6) is significantly higher in all treatments with fortified spray solutions. The larval weights range within $2.680 \mathrm{~g}$ to $3.109 \mathrm{~g}$ against control weight $2.502 \mathrm{~g}$ in $4^{\text {th }}$ instars. The same trend of enhanced larval weight in $5^{\text {th }}$ instars has also been found in each spray treatment in comparison to larval weight of control (T6), i.e. $9.741 \mathrm{~g}$ to $10.253 \mathrm{~g}>9.280 \mathrm{~g}$. The results are indicative that tissue growth of larvae treated with fortified solutions is more than untreated larvae. This in turn, may be assumed only because of more feeding response to host plant leafs. Campbell, F. L. (1927) found that nutritive liquids can be fed quantitatively to certain insects. The spray solutions containing nutrients like ascorbic acid, proline, and sodium cyclamate enhanced nutritional qualities of the host Som plant leafs. Farrar J. R. et al (1994) conducted experiments with five different nutrient based phagostimulants on the feeding behavior of six lepidopteron insects and found great response of larvae in terms of attraction and arrestancy on feed used phagostimulants in comparison to feed without phagostimulants. The phagostimulant formulation used in these spray solutions must have attracting and arresting effect on feeding leafs that ultimately increased feeding rate of Muga larvae. Further, the constituents of $\mathrm{H} 1$ formulation may also be reacted as nutrient phagostimulants. According to Nation (2001), phagostimulants are chemical compounds having an effect on insect feeding.

Further, different combinations of fortified spray chemicals exhibited differential responses on larval weight and survivability. Fortified solution with ascorbic acid, proline, sodium cyclamate used in T1 gave negative results whereas positive response achieved with the same combination mixed with host plant leaf extract as substitute of distilled water. Host plant leaf extract surely added some extra water soluble nutrient supplements increasing the nutritive qualities of feed that might increase efficiency of spray solution in T2 and, showed positive and modified results over T1. House (1969) found that provided all essential nutrients are present, the proportions of essential nutrients in a foodstuff contribute more to nutritional quality than do the absolute amounts of nutrients. According to Spencer T. Behmer (2009) most phytophagous insect's performance is modified depending on food's nutrient composition.

Again fortified chemical combinations proline-sodium cyclamate, ascorbic acid-sodium cyclamate and ascorbic acid-proline project different but all positive responses over the control T6 evidenced by their body tissue growth, survivability, cocoon weight, shell weight and silk ratio. The average body tissue growth in T3, T4 and T5 were $2.77128,2.7173,2.8861$ respectively against the average tissue growth 2.55934 recorded in control T6. So among these combinations, fortified combination ascorbic acid-proline had more effect on larval body tissue growth. On the other hand, larval survivability in the treatments was positively significant over T6. In the table-1, larval survivability after $4^{\text {th }}$ instars of all the treatments has been found higher than that of control. However, some degrees of variation exist at the end of $5^{\text {th }}$ instars in $\mathrm{T} 2$ and $\mathrm{T} 3$, still than larval survivability was significantly high in T4 and T5 (Fig. 3). Therefore, all the combinations of fortified chemicals including host plant leaf extract have positive effect but differential, on larval survivability at different growth stages of Muga silkworm. While studying on 'nuptial gift' produced by male insect that mixes with feed to attract females, Stuart Warwick et al (2009) found free amino acids particularly proline and glycine as main phagostimulatory chemicals that restrict movement of female insects. Chapman R.F. (1998) reported that proline is essential for development and as energy sources in certain insects. Nation (2001) found ascorbic acid is essential to maintain normal growth and development of some insects, particularly required by phytophagous insects. Although the final product of rearing of different treatments strictly correspondence with respective larval survivability, the cocoon qualities measured as cocoon weight, shell weight and silk ratio were found different in each treatment. Cocoon qualities of all treatments with differently fortified spray solutions were significantly higher in respect of all parameters of cocoon over T6 (table-1). Cocoon weight and shell weight in the treatments with fortified chemical solutions distributed in the range of $4.572 \mathrm{~g}-5.391 \mathrm{~g}$ against $4.219 \mathrm{~g}$ of T6 and, $0.446 \mathrm{~g}-0.627 \mathrm{~g}$ against $0.358 \mathrm{~g}$ respectively. Similarly, the distribution of silk ratio of these treatments falls within $9.637-$ 
12.496 in contrast to 8.491 of T6. In silk industries, the yean outcome is determined by numbers of cocoon production measured by effective rate of rearing (ERR) and silk ratio (SR) - higher the ERR and SR, yean production is also more. From the table-1 it is obvious that the phago-stimulant formulation (H1) fortified with ascorbic acid and sodium cyclamate gave higher number of cocoon production with more yean yield of Muga crop.

It has been concluded that the supplemented nutrients with phagostimulants works synergistically that Muga silkworm larvae responded positively in their growth and development. All the supplemented nutrients ascorbic acid, proline and Na cyclamate responded positively and may be the constituents in a nutrient supplemented phagostimulant spray formulation in their best combination for Muga silkworm. The nutrient combination ascorbic acid-proline has strong synergistic response in larval tissue growth while ascorbic acid-Na cyclamate combination has synergistic effect on cocoon production e.g. ERR. Thus, ascorbic acid is an essential nutrient supplement for both body tissue growth and survivability. Above all, it can be inferred that if host plant leaf extract is used as substitute of water in a nutrient spray solution, better yield of Muga silkworm (A. assamensis Helfer) crop may be expected.

\section{References}

Campbell, F. L. (1927). Notes on Silkworm Nutrition. Journal of Economic Entomology, Volume 20, Number 1, February 1927, pp. 88-90(3).

Chapman, R. F. (1998). The Insects, Structure and Function. 4th edition. Cambridge University Press, UK. 770pp.

Dadd, R. H. (1985). Nutrition: Organisms, In G A. Kerkut and L.I. Gilbert [Eds.], Comprehensive Insect Physiology, Biochemistry and Pharmacology, Vol. 4. Pergamon, Oxford. National Academy Press, Washington, DC. pp. 313-390.

Farrar, J. R., Robert, R., Ridgway, Richard, L. (1994). Comparative Studies of the Effects of Nutrient-Based Phagostimulants on Six Lepidoptera Insect Pests. Journal of Economic Entomology, Volume 87, Number 1, February, pp. 44-52(9).

Genc, H. (2006). General principles of insect nutritional ecology. Trakya University Journal Science. 7(1), pp 53-57.

House, H. L. (1969). Effects of different proportions of nutrients on insects. Entomologia Experimentalis et Applicata, Volume 12, Number 5; pp 651-669.

Hanife, G. E. N. Ç. (2006). General principles of insect nutritional ecology. Trakya Univ J Sci, 7(1): 53-57.

House, H. L. (1965). Insect Nutrition, in M. Rockstein (Ed.), Physiology of Insecta, 1st ed., Vol. 2, Academic Press, NY. pp. 769-813.

Kim, J. H., Mullin, C. A. (1998). Structure-phagostimulatory relationships for amino acids in adult western corn rootworm, Diabrotica virgifera virgifera. J. Chem. Ecol. 24:1499-1511.

Motoyuki Sumida and Hiroki Ueda. (2007). Dietary Sucrose Suppresses Midgut Surcease Activity in Germfree, Fifth Instars Larvae of the Silkworm, Bombyx mori. . Journal of Insect Biotechnology and Sericology, Vol. 76 (2007), No. 1 pp.1_31-1_37.

Nation, J. L. (2001). Insect Physiology and Biochemistry. Boca Raton, Fla., CRC Press. 485 pp.

Spencer T. Behmer. (2009). Insect Herbivore Nutrient Regulation. Annual Review of Entomology. Vol. 54: pp.165-187.

Stuart Warwick, Karim Vahed, David Raubenheimer and Stephen J. Simpson. (2009). Free amino acids as phagostimulants in cricket nuptial gifts: support for the 'Candymaker' hypothesis. Biol Lett., 5(2); pp.194 - 196. 
Table 1. Results of different treatments with different spray solutions measured in terms of larval weight, larval survival, ERR, cocoon weight, shell weight and silk ratio

\begin{tabular}{|c|c|c|c|c|c|c|c|c|c|c|c|c|c|c|c|}
\hline \multirow[b]{3}{*}{ 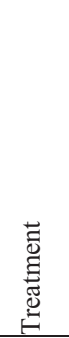 } & \multirow[b]{3}{*}{ 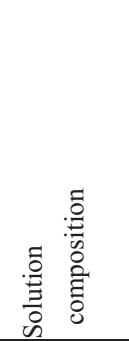 } & \multicolumn{10}{|c|}{ Growth and survivability of larvae } & \multirow{3}{*}{ 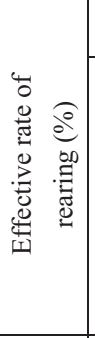 } & \multicolumn{3}{|c|}{ Quality of cocoon } \\
\hline & & \multicolumn{2}{|c|}{ first instars } & \multicolumn{2}{|l|}{$\begin{array}{l}\text { second } \\
\text { instars }\end{array}$} & \multicolumn{2}{|c|}{ third instars } & \multicolumn{2}{|c|}{ fourth instars } & \multicolumn{2}{|c|}{ fifth instars } & & \multirow{2}{*}{ 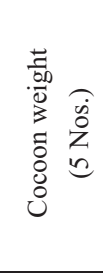 } & \multirow{2}{*}{ 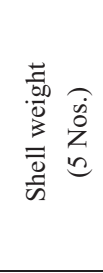 } & \multirow{2}{*}{ 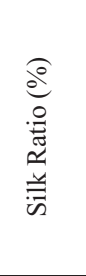 } \\
\hline & & 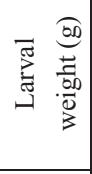 & 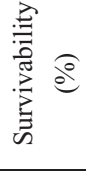 & 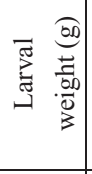 & 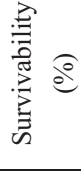 & 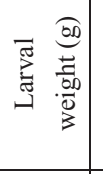 & 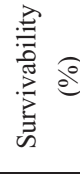 & 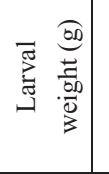 & 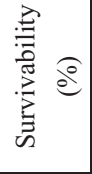 & 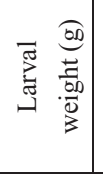 & 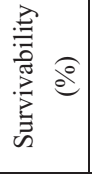 & & & & \\
\hline $\mathrm{T} 1$ & $\begin{array}{l}\mathrm{H} 1^{*} \\
\text { Ascorbic } \\
\text { acid } \\
\text { Proline } \\
\mathrm{Na} \\
\text { cyclamate }\end{array}$ & $\begin{array}{l}0.02 \\
65\end{array}$ & 97 & $\begin{array}{l}0.12 \\
0\end{array}$ & 74 & $\begin{array}{l}0.74 \\
0\end{array}$ & 63 & - & - & - & - & - & - & - & - \\
\hline $\mathrm{T} 2$ & $\begin{array}{l}\mathrm{H} 1^{*} \\
\text { Ascorbic } \\
\text { acid } \\
\text { Proline } \\
\mathrm{Na} \\
\text { cyclamate } \\
\text { Leaf } \\
\text { extract } \\
\text { (Som) } \\
\end{array}$ & $\begin{array}{l}0.03 \\
14\end{array}$ & 100 & $\begin{array}{l}0.14 \\
4\end{array}$ & 88 & $\begin{array}{l}1.44 \\
6\end{array}$ & 79 & $\begin{array}{l}2.68 \\
0\end{array}$ & 39 & $\begin{array}{l}9.74 \\
1\end{array}$ & 6.50 & 4.84 & 4.572 & 0.446 & 9.637 \\
\hline $\mathrm{T} 3$ & $\begin{array}{l}\mathrm{H} 1 * \\
\text { Proline } \\
\mathrm{Na} \\
\text { cyclamate }\end{array}$ & $\begin{array}{l}0.03 \\
84\end{array}$ & 100 & $\begin{array}{l}0.14 \\
5\end{array}$ & 97 & $\begin{array}{l}0.81 \\
4\end{array}$ & 80 & $\begin{array}{l}2.87 \\
5\end{array}$ & 40 & $\begin{array}{l}9.98 \\
4\end{array}$ & 4.84 & 4.03 & 5.391 & 0.601 & 11.148 \\
\hline $\mathrm{T} 4$ & $\begin{array}{l}\mathrm{H} 1^{*} \\
\text { Ascorbic } \\
\text { acid } \\
\mathrm{Na} \\
\text { cyclamate }\end{array}$ & $\begin{array}{l}0.03 \\
22\end{array}$ & 100 & $\begin{array}{l}0.12 \\
73\end{array}$ & 99 & $\begin{array}{l}0.74 \\
4\end{array}$ & 87 & $\begin{array}{l}2.81 \\
6\end{array}$ & 47 & $\begin{array}{l}9.86 \\
7\end{array}$ & $\begin{array}{l}17.0 \\
0\end{array}$ & $\begin{array}{l}14.3 \\
2\end{array}$ & 5.018 & 0.627 & 12.496 \\
\hline T5 & $\begin{array}{l}\mathrm{H} 1^{*} \\
\text { Ascorbic } \\
\text { acid } \\
\text { Proline }\end{array}$ & $\begin{array}{l}0.02 \\
55\end{array}$ & 100 & $\begin{array}{l}0.13 \\
6\end{array}$ & 99 & $\begin{array}{l}0.90 \\
7\end{array}$ & 85 & $\begin{array}{l}3.10 \\
9\end{array}$ & 45 & $\begin{array}{l}10.2 \\
53\end{array}$ & $\begin{array}{l}14.5 \\
0\end{array}$ & $\begin{array}{l}12.9 \\
0\end{array}$ & 5.146 & 0.523 & 10.159 \\
\hline T6 & Control & $\begin{array}{l}0.02 \\
6\end{array}$ & 100 & $\begin{array}{l}0.15 \\
97\end{array}$ & 89 & $\begin{array}{l}0.82 \\
9\end{array}$ & 80 & $\begin{array}{l}2.50 \\
2\end{array}$ & 38 & $\begin{array}{l}9.28 \\
0\end{array}$ & 6.50 & 5.65 & 4.219 & 0.358 & 8.491 \\
\hline
\end{tabular}

H1*: Phagostimulant Formulation. 


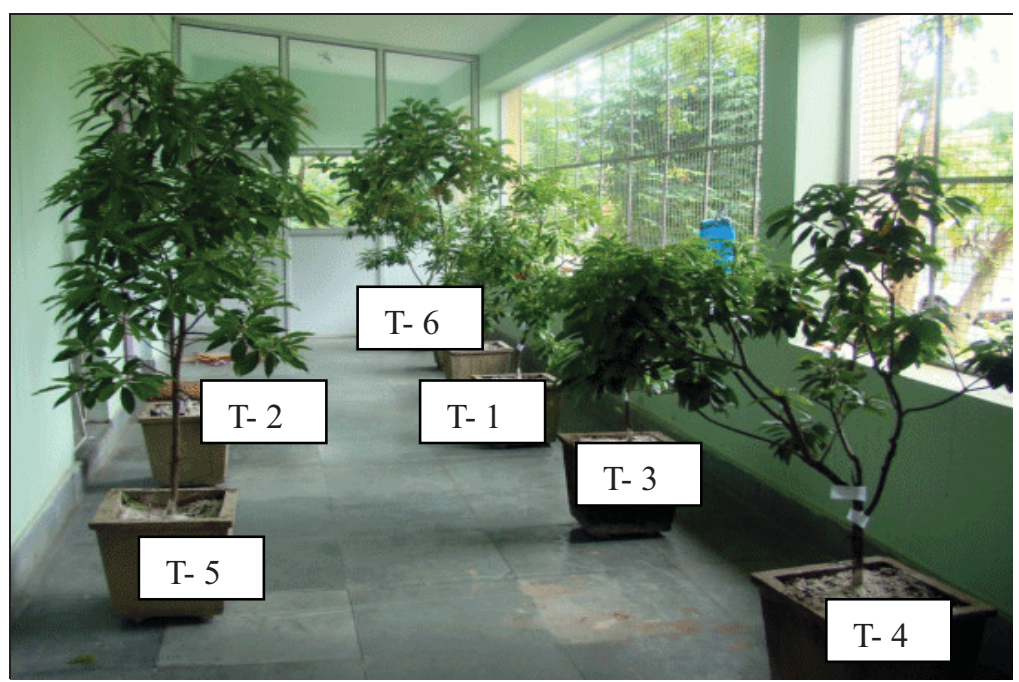

Figure 1. Pictures of six different treatments given in potted plants of Som (Muga silkworm host plant)

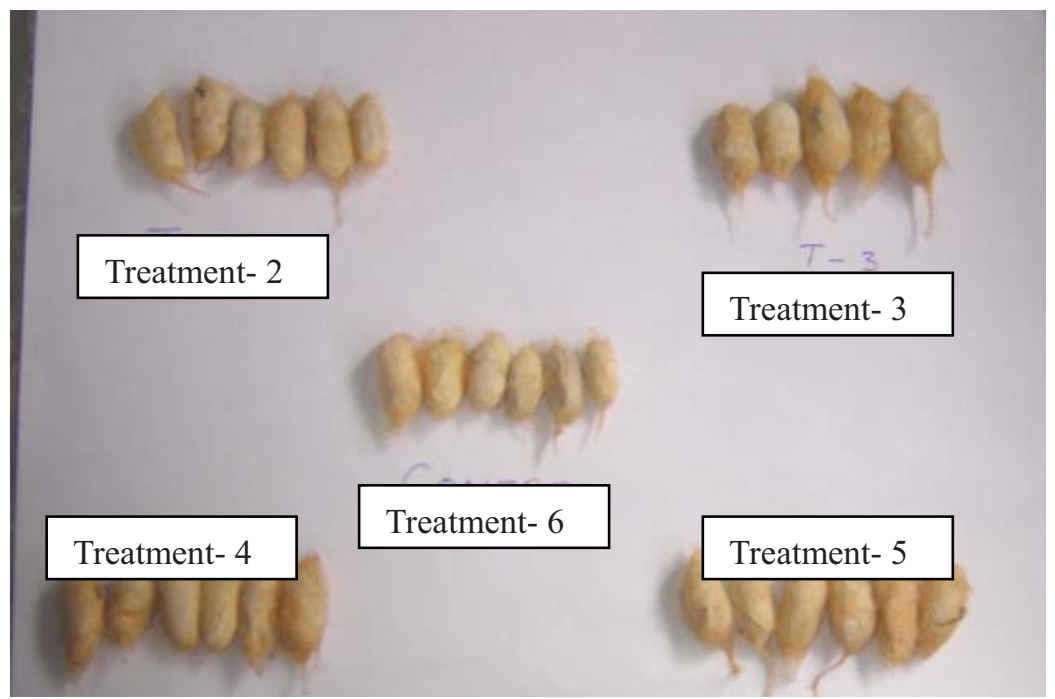

Figure 2. Pictures of cocoons harvested from six different treatments in potted plants of Som (Muga silkworm host plant) 


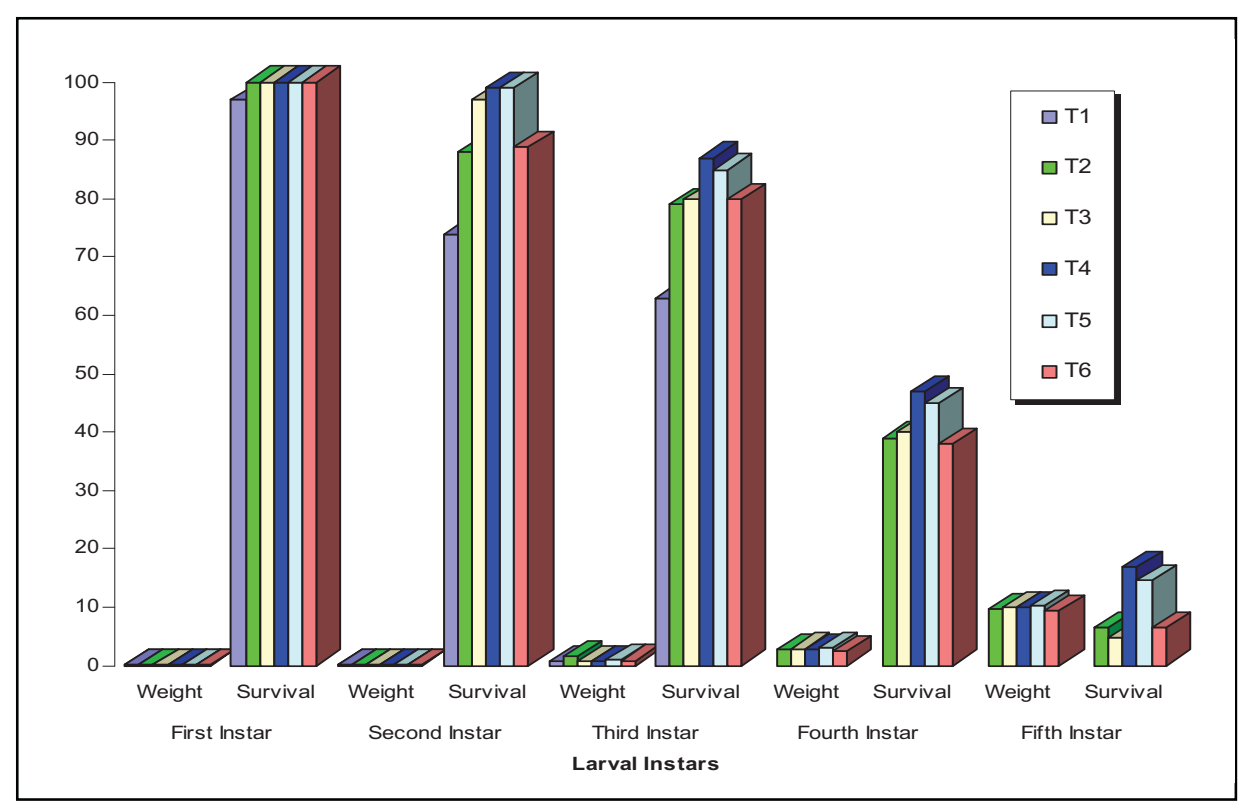

Figure 3. Graphical representation of larval weight and survivability up to $5^{\text {th }}$ instars in six different treatments 